\title{
Ongoing African measles virus genotype outbreak in Tel Aviv district since April, Israel, 2012
}

E Kopel (eran.kopel@mail.huji.ac.il) ${ }^{1}$, Z Amitai ${ }^{1}$, M Savion $^{1}$, Y Aboudy ${ }^{2}$, E Mendelson ${ }^{3,4}$, R Sheffer ${ }^{1}$

1. Tel Aviv District Health Office, Ministry of Health, Tel Aviv, Israel

2. National Centre for Measles, Mumps, and Rubella, Central Virology Laboratory, Ministry of Health, The Chaim Sheba Medical Centre, Tel Hashomer, Israel

3. Central Virology Laboratory, Ministry of Health, The Chaim Sheba Medical Centre, Tel Hashomer, Israel

4. School of Public Health, Sackler Faculty of Medicine, Tel-Aviv University, Tel Aviv, Israel

Citation style for this article:

Kopel E, Amitai Z, Savion M, Aboudy Y, Mendelson E, Sheffer R. Ongoing African measles virus genotype outbreak in Tel Aviv district since April, Israel, 2012. Euro Surveill. 2012;17(37): pii=20272. Available online: http://www.eurosurveillance.org/ViewArticle.aspx?Articleld=20272

A measles outbreak is affecting the Tel Aviv district, Israel, since April 2012. As of 10 September, 99 cases were confirmed, including 63 (64\%) migrants of Eritrean and Sudanese origin. All genotyped cases had the African B3 genotype*. The mean age of migrant and non-migrant cases was $6.0 \pm 9.6$ and $30.2 \pm 24.2$ years, respectively ( $p<0.001)$. The majority of both migrant and non-migrant cases was unvaccinated. This is the second African measles B3 genotype outbreak within the World Health Organization European region in 2012.

During the spring and summer of 2012, a large outbreak of measles affecting 99 cases as of 10 September 2012, emerged in the Tel Aviv district area. We describe the methods and findings of the epidemiological investigation that was conducted by the Tel Aviv District Health Office.

\section{Background}

Measles is a highly contagious vaccine-preventable viral disease, easily-transmissible by airborne route. The required herd immunity level for transmission interruption is $95 \%$ for two doses of a measles-containing vaccine [1].

Measles re-emerged in Israel in the past decade with several large recurrent outbreaks of genotypes D4 and D8 mainly in infants living within communities that had very low vaccination rates for age ( $<5 \%)$ such as some ultra-orthodox Jewish communities in Jerusalem [2-5]. In one of these outbreaks, the index cases were British visitors who had contracted the illness in the United Kingdom (UK) $[3,5]$. Measles is a mandatorily notifiable disease in Israel by law since 1948. Cases are notified to the district health offices from community and hospital healthcare authorities and are nationally channelled to the Division of Epidemiology of the Ministry of Health. The two-dose vaccination schedule, introduced in 1994, foresees one dose of measlesmumps-rubella (MMR) vaccine at 12 months of age and a second dose at the first grade (around 6 years of age)
[2]. The vaccine coverage for the first MMR dose in Tel Aviv district was $96 \%$ in 2009.

\section{Case definition}

The national case definition is based on laboratory confirmation (i.e. positive serologic test for immunoglobulin $\mathrm{M}$ antibody or polymerase chain reaction (PCR)) or on characteristic measles clinical symptoms (i.e. fever, rash, coryza) with an epidemiological link to a laboratory-confirmed case [2]. The case definition is similar to the current, 2010, United States (US) Centers for Disease Control and Prevention case definition for a confirmed case [6].

\section{Outbreak description}

For the outbreak investigation, data were extracted from the District Health Office files. Migrant status was defined as not having an Israeli identification card number. The migrant population includes asylumseekers, refugees, and labour-workers; excluding tourists. Frequencies and percentages were calculated for categorical variables and mean with standard deviation for age. Student's t test was applied to measure the significance of mean age difference between nonmigrant and migrant cases. The chi-squared test for sex variable and Fisher's exact test for vaccine coverage variable were used for measuring the significance of the variables' distribution between non-migrant and migrant patients. All $p$ value calculations were 2-tailed and were considered statistically significant if their value was $\leq 0.05$. The statistical analyses were performed with IBM SPSS version 19.0 (Chicago, Illinois, USA).

A total of 101 confirmed cases were notified in the Tel Aviv district between 1 January and 10 September 2012 (Figure 1), with the latest notified confirmed case having had onset of illness on 28 August 2012. Of these, 73 (72\%) were migrants. Up to 12 April 2012, only two confirmed measles cases had been identified, but the numbers subsequently increased reaching 99 confirmed cases as of 10 September 2012. The peak of the 
Confirmed measles cases ${ }^{\mathrm{a}}$ by week of onset of illness and migrant status, January-September 2012, Tel Aviv district, Israel $(\mathrm{n}=101)$

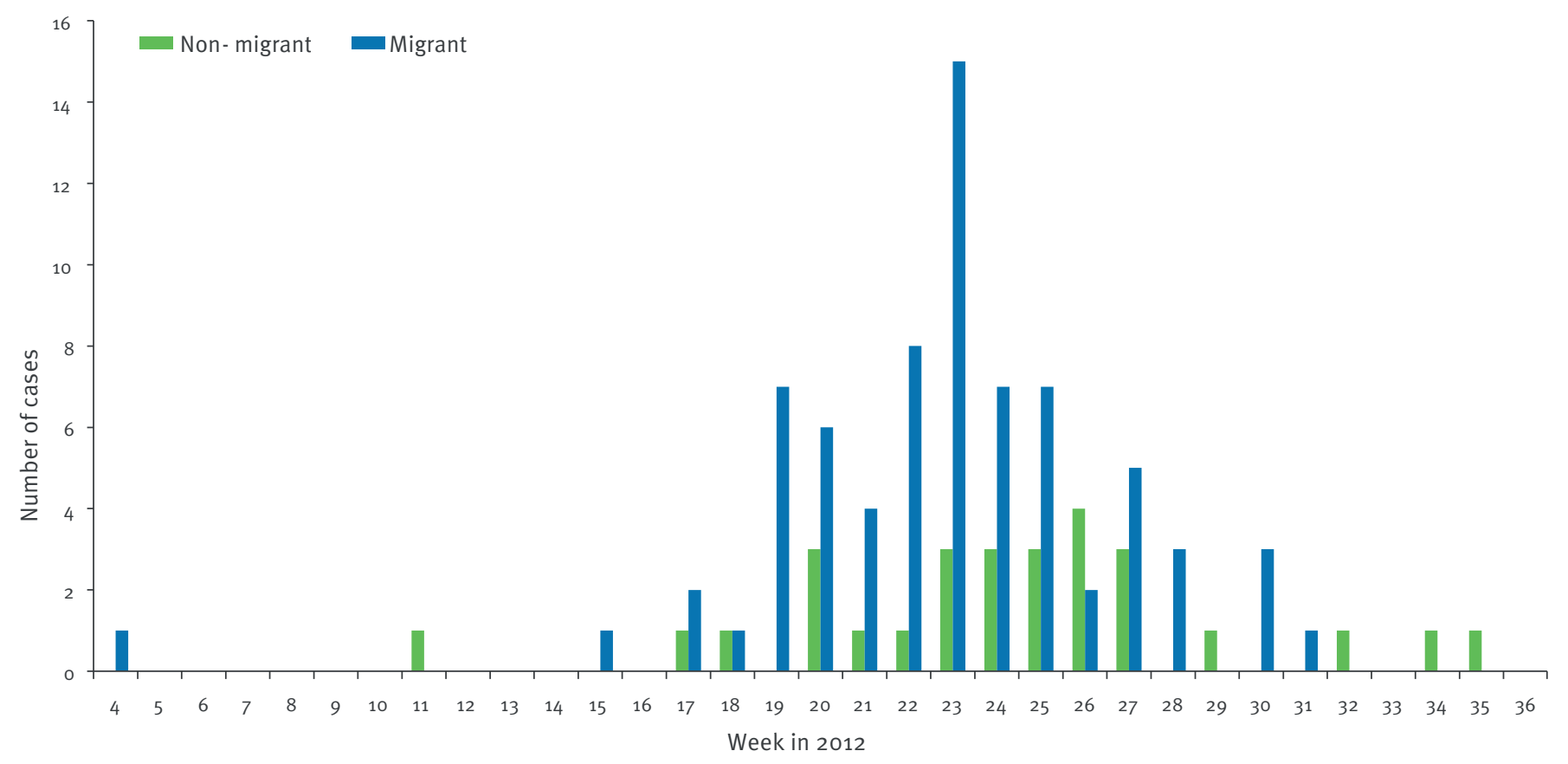

Week 4 begins on 23 January.

a Confirmed measles cases include laboratory-confirmed cases and clinical cases epidemiologically linked to laboratory-confirmed cases.

measles transmission period was observed in week 23 , between 4 and 10 June 2012, with a total of 18 confirmed cases (15 in migrants, three in non-migrants).

Of the 101 cases, 49 (49\%) were migrants of Eritrean origin and 15 (15\%) were migrants of Sudanese origin. Of the 73 total migrant cases, 55 (75\%) were males vs. 10 of $28(36 \%)$ of the non-migrant cases ( $p<0.001)$ (Table).

Mean age of migrant and non-migrant cases was $6.0 \pm 9.6$ and $30.2 \pm 24.2$ years, respectively ( $p<0.001$ ). The majority $57(78 \%)$ of the migrant cases were below three years of age, whereas 10 of 28 (36\%) of the nonmigrant cases were in this age group (Figure 2 ).

Among cases between one and six years of age, two of a total of seven migrants and two of a total of 21 nonmigrants had respectively received one dose of measles-containing vaccine $(p=0.25)$. None of the eligible cases, migrants and non-migrants alike, had two vaccine doses as appropriate for age six years and above.

\section{Viral genotyping}

The molecular characterisation of the current outbreak's measles virus was based on a fragment of 450 nucleotides (nt) of the conserved region of the nucleoprotein $(\mathrm{N})$ gene and was in concordance with World
Health Organization (WHO) standardised protocols [7]. The genotype revealed in all genotyped samples of laboratory-confirmed cases was the B3 genotype, which is predominant in Africa*.

\section{Outbreak control measures}

A number of epidemiological measures were taken in order to control the outbreak. Contact tracing was conducted and post-exposure prophylaxis up to 72 hours from exposure, was given in the form of MMR vaccine, for all susceptible (i.e. not-vaccinated for age) contacts aged six months and above, of any case, particularly for those in kindergartens, hospitals, and community healthcare centres. Early MMR vaccine administration was also offered free of charge, from nine months of age, in addition to the routine first MMR (MMR1) dose at 12 months of age, for all migrant infants (i.e. asylum seekers) visiting the Maternal and Child Health Centres in residential areas with viral transmission activity. An active outreach for routine MMR1 vaccination of migrant infants and kindergarten children took place in the Maternal and Child Health Centres located in residential areas with viral transmission activity. As a result, approximately 1,000 contacts older than six months of age and susceptible migrant infants older than nine months of age were vaccinated with one MMR vaccine dose. Moreover, all district Maternal and Child Health Centres were actively advised to in particular routinely 
TABLE

Characteristics of confirmed measles cases, by migrant status, Tel Aviv district, Israel, January-September $2012(\mathrm{n}=101)^{\mathrm{a}}$

\begin{tabular}{|c|c|c|c|}
\hline Characteristic & Migrant $(\mathrm{N}=73)$ & Non-migrant $(\mathrm{N}=28)$ & $p$ value \\
\hline Age, mean years \pm standard deviation & $6.0 \pm 9.6$ & $30.2 \pm 24.2$ & $<0.001$ \\
\hline Males n (\%) & $55(75)$ & $10(36)$ & $<0.001$ \\
\hline \multicolumn{4}{|l|}{ Place of family origin } \\
\hline Eritrea n (\%) & $49(67)$ & o (o) & NA \\
\hline Sudan n (\%) & $15(20)$ & $\mathrm{o}(0)$ & NA \\
\hline Israel n (\%) & $\mathrm{o}(\mathrm{o})$ & $28(100)$ & NA \\
\hline $\begin{array}{l}\text { Proportion of vaccinated with one dose of } \\
\text { measles-containing vaccine among measles cases aged } 1-6 \text { years }\end{array}$ & $2 / 21$ & $2 / 7$ & 0.25 \\
\hline
\end{tabular}

NA: not applicable.

a Confirmed measles cases include laboratory-confirmed cases and clinical cases epidemiologically linked to laboratory-confirmed cases. The majority $(n=99)$ of the 101 confirmed cases occurred between April and August 2012.

vaccinate all infants with MMR1 vaccine at 12 months of age, without significant delay. Finally, active guidance was provided to all district hospitals and selected community healthcare centres to validate MMR vaccine status and further vaccinate (if indicated) susceptible healthcare employees.

\section{Discussion}

We report an ongoing outbreak of measles in the Tel Aviv district area, mainly affecting unvaccinated children below three years of age of migrants of Eritrean and Sudanese origin.
In 2011, the number of measles cases was reported to be rising in both the WHO European region [8] and the US [9] where an increase in measles importations from endemic countries was observed.

In contrast to the D4 and D8 genotypes detected in outbreaks of the past decade in Israel [2-5], the $B_{3}$ genotype of this outbreak is endemic in Sub-Saharan Africa and its variants are increasingly being identified across Europe since 2005 [10]. In Israel, there was only one known case of importation to date of the $B_{3}$ genotype by a returning traveller from Angola in 2011

\section{FIGURE 2}

Confirmed measles cases by age group and migrant status, January-September 2012, Tel Aviv district, Israel (n=101)

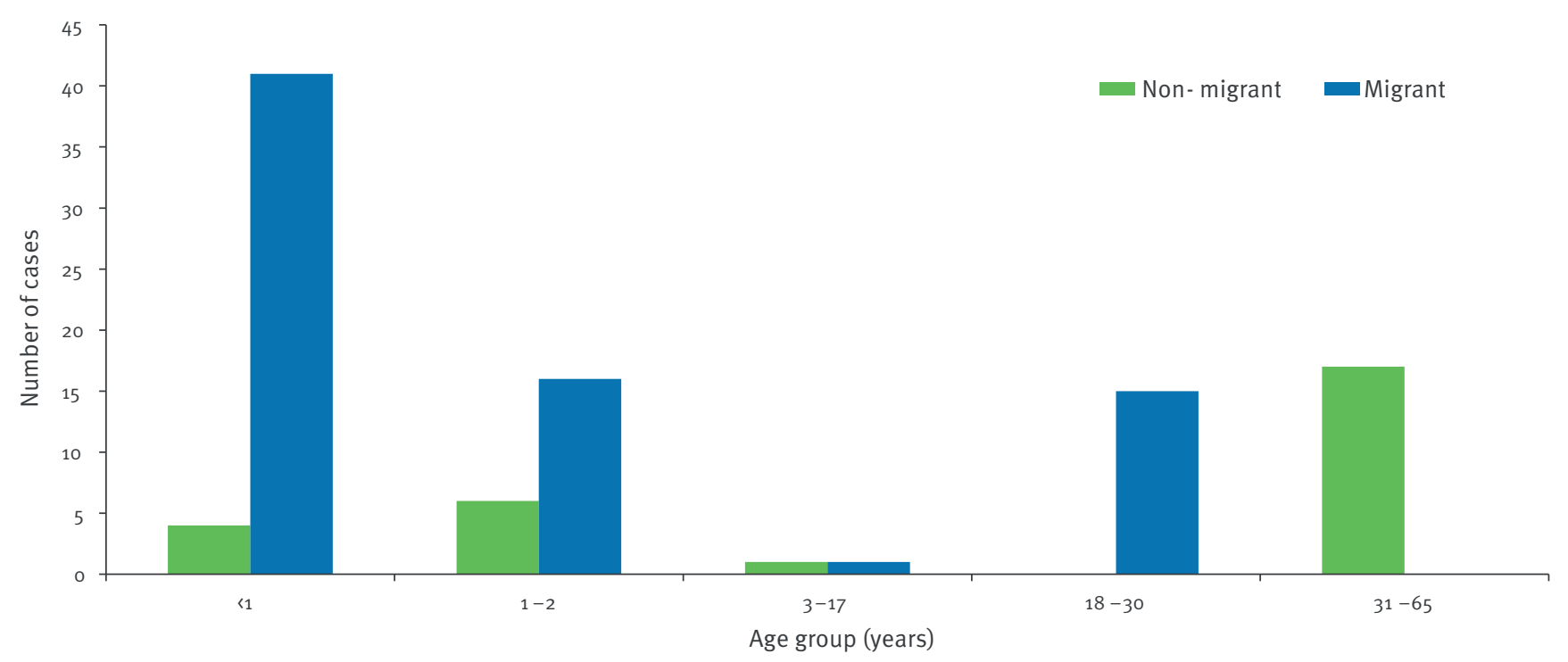

a Confirmed measles cases include laboratory-confirmed cases and clinical cases epidemiologically linked to laboratory-confirmed cases. The majority $(n=99)$ of the 101 confirmed cases occurred between April and August 2012. 
(unpublished data). Within the WHO European region, a large measles outbreak with similar epidemiological characteristics to the one reported here (e.g. affecting mainly young age groups and extremely low vaccine coverage), as well as with a predominant $B 3$ genotype, occurred in the United Kingdom (UK) in 2012 [11]. A large number of measles cases of the B3 genotype was also reported in Spain in $2011[7,8]$.

The recent higher number of measles cases and outbreaks with $\mathrm{B}_{3}$ measles genotype in countries of the WHO European region and the one described here are possibly fuelled by migration of population with low vaccine coverage from measles-endemic regions, such as Africa. In this region, the average coverage with the first dose of measles vaccine has improved between 2000 and 2010 from $56 \%$ to $76 \%$ but is still one of the lowest in the world [12]. Alternatively to a direct importation from Africa, the current measles virus outbreak's genotype could as well have been imported from Europe $[7,8,11]$. In a previous measles outbreak in 2007-08 in Israel, the first three cases were visitors from London, UK, where they had had contact with measles patients $[3,5]$.

Measures to control measles' outbreaks are generally expensive so preventing both domestic and imported measles provides a more cost-efficient solution [13]. For example, the direct cost for the public health response to a single case of imported measles in the US was recently estimated at approximately 25,000 US dollars [14]. The cost to control a small outbreak of eight patients in an asylum-seekers' shelter in Germany in 2010 was estimated to be of 90,000 Euro [15]. The obvious health benefits to the population of avoiding illness should encourage the formulation of specifically-tailored mass vaccination plans of migrant populations for vaccine-preventable diseases such as measles.

\section{Conclusions}

The outbreak reported here is the second African measles B3 genotype outbreak within the WHO European region in 2012. Mass vaccination plans, primarily reaching out to migrants, should be implemented in order to achieve higher vaccination coverage and a progress toward control of measles in the region.
* Authors' correction:

At the request of the authors, the sentence 'As of 10 September, 99 cases with B3 genotype were confirmed, including $63(64 \%)$ migrants of Eritrean and Sudanese origin.' was changed to 'As of 10 September, 99 cases were confirmed, including 63 (64\%) migrants of Eritrean and Sudanese origin. All genotyped cases had the African B3 genotype.' and the sentence 'The genotype revealed in all confirmed cases was the $B 3$ genotype, which is predominant in Africa.' was changed to 'The genotype revealed in all genotyped samples of laboratory-confirmed cases was the $B_{3}$ genotype, which is predominant in Africa.. These changes were made on 17 September 2012.

\section{Acknowledgments}

We thank Anat Scheffer, Sofia Katser, and Irina Yoabov for their continuous contribution to the epidemiological investigation.

\section{References}

1. Measles vaccines: WHO position paper. Wkly Epidemiol Rec. 2009;84(35):349-60.

2. Anis E, Grotto I, Moerman L, Warshavsky B, Slater PE, Lev B, et al. Measles in a highly vaccinated society: the 2007-08 outbreak in Israel. J Infect. 2009;59(4):252-8.

3. Stein-Zamir C, Abramson N, Shoob H, Zentner G. An outbreak of measles in an ultra-orthodox Jewish community in Jerusalem, Israel, 2007--an in-depth report. Euro Surveill. 2008;13(8). pii: 8045. Available from: http://www. eurosurveillance.org/ViewArticle.aspx?Articleld=8045

4. Stein-Zamir C, Zentner G, Abramson N, Shoob H, Aboudy Y, Shulman L, et al. Measles outbreaks affecting children in Jewish ultra-orthodox communities in Jerusalem. Epidemiol Infect. 2008;136(2):207-14.

5. Stein-Zamir C, Shoob H, Abramson N, Zentner G. Who are the children at risk? Lessons learned from measles outbreaks. Epidemiol Infect. 2012;140(9):1578-88.

6. Centers for Disease Control and Prevention (CDC). Measles (Rubeola) 2010 Case Definition. In: Case Definitions for Infectious Conditions Under Public Health Surveillance. Atlanta: CDC. [Accessed 21 Aug 2012]. Available from: http://www.cdc.gov/osels/ph_surveillance/nndss/casedef/ measles_2010.htm

7. Measles virus nomenclature update: 2012. Wkly Epidemiol Rec. 2012;87(9):73-81.

8. Increased transmission and outbreaks of measles, European Region, 2011. Wkly Epidemiol Rec. 2011;86(49):559-64.

9. Centers for Disease Control and Prevention (CDC). Measles - United States, 2011. MMWR Morb Mortal Wkly Rep. 2012;61(15):253-7.

10. Kremer JR, Brown KE, Jin L, Santibanez S, Shulga SV, Aboudy $Y$, et al. High genetic diversity of measles virus, World Health Organization European Region, 2005-2006. Emerg Infect Dis. 2008;14(1):107-14.

11. Vivancos R, Keenan A, Farmer S, Atkinson J, Coffey E, Dardamissis E, et al. An ongoing large outbreak of measles in Merseyside, England, January to June 2012. Euro Surveill. 2012;17(29). pii: 20226. Available from: http://www. eurosurveillance.org/ViewArticle.aspx?Articleld=20226

12. Simons E, Ferrari M, Fricks J, Wannemuehler K, Anand A, Burton A, et al. Assessment of the 2010 global measles mortality reduction goal: results from a model of surveillance data. Lancet. 2012;379(9832):2173-8.

13. Takahashi K, Ohkusa Y, Kim JY. The economic disease burden of measles in Japan and a benefit cost analysis of vaccination, a retrospective study. BMC Health Serv Res. 2011;11:254.

14. Coleman MS, Garbat-Welch L, Burke H, Weinberg M, Humbaugh $K$, Tindall A, et al. Direct costs of a single case of refugeeimported measles in Kentucky. Vaccine. 2012;30(2):317-21.

15. Takla A, Barth A, Siedler A, Stöcker P, Wichmann O, Deleré Y. Measles outbreak in an asylum-seekers' shelter in Germany: comparison of the implemented with a hypothetical containment strategy. Epidemiol Infect. 2012;140(9):1589-98. 